Article

\title{
Reprocessing of a Southern Chilean Zn Tailing by Flotation-A Case Study
}

\author{
Bent Babel ${ }^{1, *, \dagger}$, Maike Penz ${ }^{2, *, \dagger}$, Edgar Schach ${ }^{1}$, Stefanie Boehme ${ }^{2}$ and Martin Rudolph ${ }^{1}$ (i) \\ 1 Helmholtz Institute Freiberg for Resource Technology, Helmholtz-Zentrum Dresden-Rossendorf, \\ 09599 Freiberg, Germany; e.schach@hzdr.de (E.S.); m.rudolph@hzdr.de (M.R.) \\ 2 Department of Mineralogy of the Technische Universität Bergakademie Freiberg, 09599 Freiberg, Germany; \\ StefanieBoehme@outlook.de \\ * $\quad$ Correspondence: b.babel@hzdr.de (B.B.); penz.maike@web.de (M.P.); Tel.: +49-351-260-4481 (B.B.) \\ + These authors contributed equally to the study.
}

Received: 1 June 2018; Accepted: 9 July 2018; Published: 11 July 2018

\begin{abstract}
The reprocessing of tailings can have economic and environmental benefits compared to the processing of primary ore deposits. In this paper we present the characterization of a tailings dam in southern Chile by means of mineralogical and geochemical investigations, focusing on sphalerite and trace elements with the aim to investigate a potential reprocessing. The assessment is followed by a flotation study, focusing on the recovery of sphalerite with a high selectivity towards sulfidic and non-sulfidic gangue minerals. An in-depth analysis of a selected test based on mineral liberation analysis data is used to refine the liberation, concentration and flotation weighting function for future investigations.
\end{abstract}

Keywords: geometallurgy; flotation; sphalerite; tailings; reprocessing

\section{Introduction}

\subsection{Valorization of Tailings}

Millions of tons of ore are processed annually by the mining industry and more than $95 \%$ of the mined material is disposed as waste rock or tailings [1]. Therefore, investigations on tailings are not just of interest in terms of environmental issues like visual impact, structural stability, release of radiation, air and soil pollution, or contamination of ground and surface waters [2,3], but also for economic reasons.

From an economic perspective, not only residual amounts of the initial primary resource of the mining operation, but the overall potential of value elements should be considered due to changing demands as a result of technological developments [4]. Advances in analytical techniques like the mineral liberation analysis (MLA) $[5,6]$ as well as improvements in machinery, for example in fine and coarse particle recovery [7-9] or flotation techniques [10,11], can be applied to recover valuables.

Even if most of the materials contained in the tailings are not considered to be of economic value or being profitable for new exploitation, most tailings contain increased concentrations of base metals such as $\mathrm{Cu}, \mathrm{Fe}, \mathrm{Ni}, \mathrm{Zn}[12,13]$ or traces of $\mathrm{Bi}, \mathrm{Au}, \mathrm{Ag}$ and rare earth elements. Therefore, some elements can be regarded either as primary- or as by-products increasing the profitability of a potential reprocessing. Bi for example is used in the chemical, medical, cosmetic and metallurgical industry [14].

In addition to reprocessing of tailings, Lottermoser compiled alternative uses for mine wastes in the framework of a mine waste hierarchy e.g., the utilization of tailings as backfill material, clay-rich tailings for manufacturing purposes, Mn-rich tailings in agro-forestry or building materials and 
$\mathrm{Cu}$-rich tailings as extenders for paints [15]. Compared to primary ore deposits, tailing dams have specific advantages such as an exposed surface, well-defined tonnages and that the material is already crushed and milled [16,17]. These properties will reduce the operational and capital costs of a potential reprocessing operation. However, the disadvantages are due to the physical properties of the tailing's material like an unfavorable particle size distribution $[3,9,17]$, either being too fine or too coarse to be recovered by certain processes. Additionally, an insufficient liberation degree and alterations of bulk and surface properties limit potential reprocessing. Examples for reprocessing studies were reported on tailings containing tin [9,16], tungsten [18], cobalt [19], copper [11,17,19,20] and zinc [21].

\subsection{Material Characterization}

The tailings investigated in this study originate from an operation processing a deposit of $25 \mathrm{~km}^{2}$ consisting of various stratiform ore bodies [22]. A series of magmatic and hydrothermal events lead to the typical skarn mineralization of sphalerite, pyrrhotite, pyrite, arsenopyrite, as well as minor amounts of galena and chalcopyrite. In the southeast part of the deposit, the dominating gangue mineralization is represented by garnet, pyroxene and amphibole, while in the northwestern part of the district alteration minerals like sericite and chlorite are dominant. The concentration of $\mathrm{Au}$ and $\mathrm{Pb}$ is also higher in the northwestern area than in other locations. The $\mathrm{Zn}$ concentration of the different ore bodies is almost unique, but in the northern district area sphalerites show lower Fe concentrations compared to the south [22]. This is explained by lower fluid temperatures during the mineralization. The difficulty of ore dressing of this deposit lies in the various mineralizations and in the different composition and alterations of the country rock. Elements recovered due to their economic value are gold, silver, zinc and lead.

The mineralogical composition of the "old tailing" material was analyzed by polarization microscopy, X-ray powder diffraction (XRD), mineral liberation analysis (MLA), hand-held X-ray fluorescence spectroscopy ( $\mathrm{h}-\mathrm{XRF}$ ), scanning electron microscopy with energy dispersive $\mathrm{X}$-ray spectroscopy (SEM-EDX) and electron probe microanalysis (EPMA). Preliminary studies revealed that the main mineral phases of this southern Chilean tailing are diopside, epidote, chlorite, garnet (andradite), actinolite, calcite, quartz, pyrite, pyrrhotite, sphalerite and magnetite.

The sampling of the deposit took place at the "old tailing"-district, which has been inactive for about 40 years. Profile B1 was divided into two geological separated horizons (J and H). A large sample (about $100 \mathrm{~kg}$ ) was taken of each one. For the mineralogical analysis and the flotation process the samples of the horizons were homogeneously mixed and around $4 \mathrm{~kg}$ of the material was divided into required subsamples.

The sampling of the A1 samples was carried out in 2014 and was taken close to the profile B1. One profile with different horizons (A-F) was sampled and the sample A1F has been examined in detail.

\subsection{Procsssing Options for Sphalerite Tailings in a Froth Flotation Context}

The purpose of the flotation study is to evaluate the possible reprocessing of the tailings dam and to gather experimental data for a refinement of the earlier proposed liberation, concentration and flotation (LFC) weighing function [16].

Due to a limited amount of material the focus of the flotation experiments is on the reagent regime and the recovery of sphalerite with a high selectivity against gangue minerals, also considering the increased amounts of iron contained in the sphalerite [22]. In literature, the high iron variety of sphalerite is referred to as marmatite and it is known for a higher reagent consumption and lower flotation kinetics [23,24]. In the flotation test work this variant will be referred to as "high iron sphalerite". Due to the preprocessing of the material and its deposition in a tailings dam, mineral surface alterations are likely as well as the uncontrolled activation of minerals by copper ions. Possible reasons for the losses of sphalerite in the tailing stream are an unfavorable particle size distribution, a partial or insufficient hydrophobization of sphalerite due to the high iron content, resulting in lower 
flotation kinetics $[23,24]$, and an insufficient amount of $\mathrm{CuSO}_{4}$, which is needed to activate marmatite, as it is proportional to the amount of iron present in the mineral [23]. Therefore, a non-optimal reagent regime or insufficient activation might result in the losses.

Minerals likely to cause selectivity issues for sphalerite flotation are galena, pyrite, pyrrhotite, chalcopyrite and finally arsenopyrite, as a possible source of a penalty element. Usually sphalerite is depressed to float other sulfides at mild $\mathrm{pH}$ values and is separated from pyrite at high $\mathrm{pH}$ with the activation of copper ions and typical sulfide collectors such a xanthates in a subsequent step [25]. The $\mathrm{pH}$ for sphalerite flotation varies from 10.5 to 11.8 [23]. As the standard activator, $\mathrm{CuSO}_{4}$ is used and a critical copper sulphate concentration was reported in Reference [26,27]; the added amount of $\mathrm{CuSO}_{4}$ is one important test work parameter, also reflecting the higher activator consumption in high iron sphalerite flotation [25]. Tong et al. also suggested the activation of high-iron sphalerite by ammoniacal copper (II) solution [28]. The mechanisms relevant for sphalerite flotation have been discussed in detail in reference [24].

In the context of tailings flotation, Yang et al. described reactivation mechanisms for marmatite contained in cyanide leaching tailings with hydrogen peroxide, sodium hypochlorite, sodium metabisulfite and copper sulfate [21]. Additional techniques, which might be suitable for the removal of oxidation products from sulfide surfaces or tailings in general, were reported in reference [29], like sonication and attritioning. Videla et al. reported a slight improvement of recovery and grade for fine copper tailings by ultrasound treatment linking it to a surface cleaning and a fine particle agglomeration effect [11]. Further possible options to improve the process performance are $\mathrm{O}_{2}$ conditioning as reported by Reference [30], an optimization of the reagent regime for the utilization of $\mathrm{CuSO}_{4}$, as the collector choice should be xanthate as the primary collector and thionocarbamate as the secondary collector [23]. The application of polyacrylamide polymer depressants (PAM) with a preferential polymer adsorption on pyrite and variants of depressant addition [30] are applied, in case the reagent regime is not sufficiently selective. Additionally, a good water quality with low concentrations of $\mathrm{Pb}^{2+}$ and $\mathrm{Fe}^{2+}$ amongst others is beneficial [24]. Another suggested depressant is dimercapto-propane sulphonate (DMPS) at a $\mathrm{pH}$ range from $\mathrm{pH} 4.36$ to $\mathrm{pH} 8$ with sodium silicate as an additional dispersant in the presence of butyl xanthate [31], and finally sodium glycerine-xanthate using $\mathrm{Cu}^{2+}$ as an activator and butyl xanthate as the collector as suggested in Reference [32]. With this variety of options reported in the literature, the chosen process parameters were set close to the initial flowsheet parameters. To evaluate the process results the metallurgical target specifications for sphalerite concentrates are summarized in Table 1 [33]. These specifications cannot be achieved by a single rougher step bulk flotation as performed in this test work, but give implications to improve the selectivity of the process.

Table 1. Metallurgical target specifications.

\begin{tabular}{cc}
\hline Element & Composition Range \\
\hline $\mathrm{Zn}$ & 47 to $56 \%$ \\
$\mathrm{Fe}$ & $<10 \%$ \\
$\mathrm{~Pb}$ & $<3 \%$ \\
$\mathrm{Cu}$ & $<2 \%$ \\
$\mathrm{~S}$ & 30 to $32 \%$ \\
\hline
\end{tabular}

\subsection{Scope of Work}

The scope of this paper is the characterization of a tailings dam in southern Chile in terms of potential primary- and by-products with the aim to assess their valorization. Froth flotation is identified as a feasible process and as the outcome of flotation processes is strongly dependent on surface liberation and particle size of the targeted minerals, these parameters are analyzed in detail by MLA based data. The earlier proposed LFC weighing function [16] is further refined by experimental results and this geometallurgical concept can in the future be utilized to highlight the distribution of 
reprocessing potentials in a 3D model of the tailings dam, accounting for the variability of concentration, surface liberation and floatable particle size of valuables.

\section{Materials and Methods}

This section contains the description of applied analytical methods with their sample preparation procedure, the applied chemical reagents, the sample preparation procedure for the flotation test work, and a description of the used flotation protocol.

\subsection{General Sample Preparation for Analytical Methods}

Four samples were investigated i.e., A1F and B1 ( $\mathrm{J}$ and $\mathrm{H}$ ) as bulk samples representing different sample sites and horizons, as well as a heavy mineral concentrate A1F-SM. In order to prepare the samples for the analytical methods, the grain size fraction $>200 \mu \mathrm{m}, 200-63 \mu \mathrm{m}, 63-20 \mu \mathrm{m}$ were produced. For the preparation of the heavy mineral concentrate A1F-SM a subsample of A1F was further processed by gravity separation with bromoform $\left(\varrho=2.89 \mathrm{~g} / \mathrm{cm}^{3}\right)$ and magnetic separation.

Polished thin sections of the 63-200 $\mu \mathrm{m}$ fraction of the heavy mineral concentrate A1F-SM and the bulk samples A1F and B1 were produced by the grinding laboratory of DDT GmbH and Co., KG in Bochum, Germany. The mineral grains were embedded under a vacuum in blue epoxy resin and polished to a thickness of $30 \mu \mathrm{m}$. The samples were analyzed via polarization microscopy, X-ray powder diffraction, electron probe microanalyzer, energy-dispersive $\mathrm{X}$-ray spectroscopy and mineral liberation analysis.

\subsubsection{X-ray Powder Diffraction}

To determine the mineral composition of the tailings material the samples or prefabricated concentrates were analyzed by $\mathrm{X}$-ray diffraction. First, the samples were fine ground until a grain size of $4 \mathrm{~mm}$ was reached. The samples were mixed with an internal standard, in this case with $20 \mathrm{wt} \%$ of codundum, to determine the amorphous phase (i.e., organic) content. Afterwards the material is quartered and approximately $2 \mathrm{~mL}$ of the sample is measured. $10 \mathrm{~mL}$ of technical ethanol $(69 \%)$ is added to the prepared sample. This mixture is ground in a McCrone mill for $10 \mathrm{~min}$, to minimize micro-adsorption effects caused by large crystals. After this procedure, the sample is washed clean, dried and homogenized with a mortar and an Ardenne vibrator, followed by the preparation of the cuvette for the measurement. The preparation depends on the material and desired measuring result. In this case, a combination of side loading [34] and sieving the sample through a $200 \mu \mathrm{m}$ sieve into the cuvette were used to minimize textural and orientation effects.

All measurements were realized with an X-ray diffractometer PANalytical Empyrean (Malvern, UK) (radius $240 \mathrm{~mm}$ ) at the Helmholtz Institute Freiberg for Resource Technology (HIF) and the URD 6 (Seifert-FPM) at the Mineralocigal Laboratory at the Department of Mineralogy of the Technische Universität Bergakademie Freiberg. The radiation source is a Co radiation at $35 \mathrm{kV}$ and $35 \mathrm{~mA}$ for the PANalytical Empyrean and $40 \mathrm{kV}$ and $30 \mathrm{~mA}$ for the URD6. The PANalytical Empyrean has an automatic divergence aperture, two detectors (one proportional counter with monochromator and a PIXcel 3-D Medipix $1 \times 1$ semiconductor detector (with Fe-filter)) and a sample changer can be applied, which holds up to 45 samples. For the measurements, a common Xe-proportional counter detector in combination with a graphite monochromator was used for the elimination of the K- $\beta$ and fluorescence radiation. For the measurement, a routine program with a step size of $0.015^{\circ} 2 \theta$ at the interval of $5-80^{\circ} 2 \theta$ and a step time of 8 (20) s/step was used. The software package HighScore 3.0 by PANalytical was used for a mineral identification. For the measurements at the URD6 the detector with proportional counter and graphite monochromator, a step size of $0.02^{\circ} 2 \theta$ and a steptime of $2 \mathrm{~s} /$ step was applied. The evaluation of the diffractogram and quantitative phase determination via the Rietveld refinement was performed with the open source software package Profex/BGMN v3.9.1 [35]. Structure models for the Rietveld analysis based on the data of the optical microscopy, $\mathrm{h}-\mathrm{XRF}$ data and 
results from previous measurements of similar samples of the same deposit, but different locations, were selected.

\subsubsection{Polarization Microscopy}

The polarizing microscope is a valuable tool for a first qualitative and quantitative determination of existing minerals, inclusions and specific elements. The characterization of the gangue minerals was performed with transmitted light, while for the ore phases reflected light was giving the best results. The used microscope is a ZeissAxio Imager A1m with AxioCam MRc5 camera and the AxioVision 4.8 software. The measurements were performed at the Department of Mineralogy of the Technische Universität Bergakademie Freiberg.

\subsubsection{Scanning Electron Microscopy-Energy Dispersive X-ray Spectroscopy (SEM-EDX) and EPMA}

Further analyses for mineral determination (qualitative analysis) of the vapor-deposited thin sections were carried out on a scanning electron microscope JEOL JCM 5700 (JEOL, Tokyo, Japan) carry scope equipped with an EDX detector (Bruker, Billerica, MA, USA). The software of the carry scopes SmileShot (JEOL, Tokyo, Japan) v1.22-2007 was used for detail shots in BSE mode, and for evaluation of the EDX data the corresponding Bruker software (QUANTAX 200).

EDX measurements were performed at a working distance of $\sim 20 \mathrm{~mm}$ and an excitation voltage of $20 \mathrm{kV}$. In general, the beam current in tungsten cathodes is around $1 \mathrm{pA}$ to $1 \mu \mathrm{A}$. The measurements took place at the Department of Mineralogy of the Technische Universität Bergakademie Freiberg.

\subsubsection{Mineral Liberation Analyzer (MLA)}

The mineral liberation analyzer is an automated analytical tool, particularly for qualitative determination of the mineral content of natural and industrial materials. In principle, it is a scanning electron microscope with two detectors (EDX) and a special software for the consideration of mining and mineral processing aspects like grain size distribution, liberation degree, mineral associations, etc. The measurements were performed with a Quanta FEG 650 and the sphalerite varieties were separated into a $-20 \%$ iron and a $+20 \%$ iron class based on spectral information. The data was processed by the MLA image processing tool box and analysis was performed by MLA dataview and an R routine. For the binning into the size and liberation classes the equivalent circle diameter and the surface liberation of the particles were used. The sample preparation was performed in the sample preparation laboratory of the HIF. To increase the total amount of particles per size and liberation class two grain mounts per concentrate, and tailings fraction were produced.

\subsubsection{Handheld X-ray Fluorescence Spectroscopy (h-XRF)}

The hand-held XRF analyzer Niton XL3t (Thermo Fischer Scientific, Waltham, MA, USA) was used during the sampling in the field as well as during the analysis in the laboratory of the sample B1. This hand-held X-ray fluorescence sensor system is commonly used for quality assurance, material identification, precious metal analysis, environmental analysis and can also be applied to detect various elements and metals in mining and exploration. The measurements can be carried out under field conditions and with a sample chamber under laboratory conditions allowing good comparability between field and laboratory measurements. The detection limit for base metals in these instruments are low and it offers certain settings for different applications.

\subsection{Chemicals}

The collector used in the flotation test work is Danafloat 507-B as a mixture of dithiophosphate, thiocarbamate and iso-butanol supplied by Danafloat. The $\mathrm{pH}$-value of the pulp was set with CaO. $\mathrm{CuSO}_{4}$ (Carl Roth, Karlsruhe, Germany) was used as an activator and KCN (provided by UVR-FIA $\mathrm{GmbH}$, Freiberg, Germany) as an additional depressant, if applied. 4-Methyl-2-pentanol (MIBC, 
Sigma Aldrich, Saint Louis, MO, USA) was used as the frother. The relevant parameters for the trials are summarized in Table 2 and are based on values reported in literature [23].

Table 2. Parameters for preliminary flotation tests.

\begin{tabular}{cccccc}
\hline Sample & $\mathbf{p H}$ & $\mathbf{C u S O}_{\mathbf{4}} \mathbf{g} / \mathbf{t}$ & $\mathbf{M i B C}$ in $\mathbf{g} / \mathbf{t}$ & Danafloat 507-B g/t & KCN g/t \\
\hline B1_TP_1 & 11 & 250 & 25 & 25 & 0 \\
B1_TP_2 & 12 & 100 & 25 & 25 & 0 \\
B1_TP_3 & 12 & 0 & 25 & 25 & 0 \\
B1_TP_4 & 11 & 100 & 25 & 25 & 0 \\
B1_TP_6 & 11.5 & 500 & 35 & 40 & 0 \\
B1_TP_7 & 10.5 & 500 & 50 & 50 & 100 \\
B1_TP_8 & 11 & 600 & 50 & 50 & 200 \\
\hline
\end{tabular}

\subsection{Material Preparation}

The B1 sample was dried at $50{ }^{\circ} \mathrm{C}$ to avoid surface oxidation of the sulfide minerals and its density was measured by a helium pycnometer; to ensure representative samples for the flotation test work B1 were split by a Retsch PT 100 rotary splitter into $\sim 480 \mathrm{~g}$ fractions. The subsamples are referred to as TP_1 to TP_8. The concentrates and tailings were collected, dried at $50{ }^{\circ} \mathrm{C}$ until mass constancy and weighed. Before submitting the samples to analytical preparations the samples were de-agglomerated and the tailings sample was spilt with a rotary splitter to archive suitable sample masses.

\subsection{Flotation Test Work}

The flotation tests were carried out in a $1.5 \mathrm{~L}$ bottom driven Magotteaux flotation cell. The mass concentration of solids in the pulp was set to $28 \%$, the airflow rate was $3 \mathrm{~L} / \mathrm{min}$, the agitator speed was set to $500 \mathrm{rpm}$. The total time per trial was $14 \mathrm{~min}$, i.e., $10 \mathrm{~min}$ of conditioning steps and $4 \mathrm{~min}$ of flotation with three concentrates collected until minute 1, 2 and 4 with a skimming frequency of six strokes per min. The first conditioning step was the adjustment of pulp $\mathrm{pH}$, followed by the addition of $\mathrm{CuSO}_{4}$. The second conditioning step started after $5 \mathrm{~min}$ with the addition of the collector followed by the addition of MIBC after $9 \mathrm{~min}$. The pulp $\mathrm{pH}$ was regulated during the conditioning if needed and the water level was held constant during the course of the experiment. If KCN was applied as an additional depressant, $5 \mathrm{~min}$ was added ahead of the addition of the activator.

\section{Results}

\subsection{Mineralogical Characterization}

This section contains the results of the mineralogical characterization of the tailings material. Table 3 shows that compared to the samples of B1, A1F-Bulk and A1F-SM do not contain arsenopyrite, hornblende, gypsum and enstatite, but actinolite and magnetite. The sphalerite is enriched to $1.9 \mathrm{wt} \%$ in A1-SM, which is the heavy mineral sample of A1F-Bulk. In the bulk samples A1F, B1-H and B1-J, the concentration of the sphalerite is below $1.0 \mathrm{wt} \%$. The pyrrhotite content is twice as high in both A1 samples and in B1-J compared to B1-H (3.2 wt \%). The pyrite content varies between 1.0-3.4 wt \% in the bulk samples of the different profiles A1 and B1, but is enriched in A1-SM (8.2 wt \%). The same enrichment applies for saponite and the epidote in sample A1F-SM. B1-J has a high amount of chlorite (17.1 wt \%), twice as high as in the other samples. The concentrations of other detected mineral phases are in the same magnitude in all samples. One reason for the different concentrations of the samples, is a result of the heavy mineral pre-concentration, for example pyrite of the A1F-SM. Additionally peak superimpositions of the minerals and the complexity of the mineral compounds in the samples can also result in differing concentrations. 
Table 3. X-ray powder diffractometric values for fractions from the old tailing in wt $\%$.

\begin{tabular}{ccccc}
\hline Mineral Phases & A1F-Bulk & A1F-SM & B1-H & B1-J \\
\hline Actinolite & $5.1 \pm 1.1$ & $5.7 \pm 1.2$ & - & - \\
Garnet (And) & $1.1 \pm 0.4$ & $2.1 \pm 0.5$ & - & $0.4 \pm 0.1$ \\
Calcite & $10.8 \pm 0.9$ & $7.0 \pm 0.9$ & $11.5 \pm 0.3$ & $9.9 \pm 0.3$ \\
Chlorite & $7.9 \pm 1.0$ & $10.7 \pm 1.3$ & $8.9 \pm 0.4$ & $17.1 \pm 0.8$ \\
Diopside & $2.8 \pm 1.2$ & $5.8 \pm 1.1$ & $2.7 \pm 0.2$ & $2.4 \pm 0.3$ \\
Epidote & $5.2 \pm 1.2$ & $9.2 \pm 1.8$ & $2.8 \pm 0.2$ & $2.1 \pm 0.3$ \\
Magnetite & $0.8 \pm 0.3$ & $1.8 \pm 0.5$ & - & - \\
K-Felspar (Microcline) & $1.9 \pm 0.9$ & - & - & $1.6 \pm 0.3$ \\
Muscovite & $1.1 \pm 0.6$ & - & - & $3.3 \pm 0.4$ \\
Plagioclase & $1.2 \pm 0.7$ & - & - & $1.4 \pm 0.3$ \\
Pyrite & $3.4 \pm 0.3$ & $8.2 \pm 0.5$ & $2.0 \pm 0.1$ & $1.0 \pm 0.1$ \\
Pyrrhotite & $7.0 \pm 0.4$ & $10.4 \pm 0.6$ & $3.2 \pm 0.1$ & $8.4 \pm 0.2$ \\
Quartz & $28.6 \pm 1.2$ & $8.3 \pm 0.5$ & $21.7 \pm 0.4$ & $23.1 \pm 0.5$ \\
Saponite & $10.2 \pm 2.2$ & $18.2 \pm 3.0$ & $4.9 \pm 0.6$ & $2.7 \pm 0.4$ \\
Sphalerite & $0.9 \pm 0.2$ & $1.9 \pm 0.2$ & $0.2 \pm 0.03$ & $0.9 \pm 0.04$ \\
Arsenopyrite & - & - & $0.3 \pm 0.07$ & $1.0 \pm 0.1$ \\
Hornblende & - & - & $2.4 \pm 0.2$ & - \\
Gypsum & - & - & $2.2 \pm 0.1$ & $1.8 \pm 0.1$ \\
Enstatite & - & - & - & $2.5 \pm 0.3$ \\
Amorphous and others & $12.1 \pm 4.5$ & $8.8 \pm 5.7$ & $37.0 \pm 1.2$ & $20.9 \pm 1.8$ \\
\hline & & & &
\end{tabular}

Complementary to the XRD measurement the mineral content was determined by MLA. The results shown in Table 4 should not be interpreted as quantitative data. In this example the choice of the mineral names is inconvenient, for example plagioclase is also indicated as anorthite, similar for amphibole, which actually represents a general term for the Fe-gedrite and hornblende. Ca-Mg-siderite is also a Ca-Mg-Fe carbonate. However, MLA datasets bear valuable additional information, which will be discussed in a paragraph below.

Table 4. Mineral content of A1F-SM in wt \%, determined using mineral liberation analyzer.

\begin{tabular}{ccc}
\hline Mineral Phases & A1F-SM & B1-J \\
\hline Amphibole & 17.1 & - \\
Apatite & 0.3 & 0.3 \\
Biotite & 0.6 & 1.2 \\
Ca-Mg-Fe-Carbonate & 0.5 & 0.6 \\
Chlorite & 1.0 & 1.8 \\
Fe-Gedrite & 13.3 & 16.7 \\
Hornblende & 0.1 & 0.1 \\
Jacobsite & 0.1 & - \\
Muscovite & 1.2 & 2.8 \\
Orthoclase & 0.3 & 1.6 \\
Pyrite & 28.5 & 26.3 \\
Rutile & 0.1 & 0.1 \\
Sphalerite & 2.9 & - \\
Ca-Mg-Siderite & 0.2 & 0.3 \\
Epidote & 5.0 & 0.7 \\
Fe-Oxide & 8.5 & 1.5 \\
Ilmenite & 0.1 & - \\
Jarosite & 1.4 & 1.3 \\
Olivine & 0.1 & - \\
Plagioclase & 0.4 & 0.6 \\
Quartz & 5.6 & 22.3 \\
Siderite & 0.6 & - \\
Arsenopyrite & - & 0.5 \\
Titanite & 0.9 & 0.1 \\
Anhydrite & - & 1.7 \\
Mn-Fe-Mg-Calcite & - & 1.7 \\
Fe-Mn-Oxide & - & 0.1 \\
Anorthite & - & 1.1 \\
\hline & &
\end{tabular}




\subsubsection{Determination of the Mineral Content by Polarization Microscopy and SEM-EDX or EPMA-EDX}

The mineral phases examined by polarization microscopy of the A1F-Bulk sample were quartz, calcite, minerals of the epidote group, garnet (spessartine andradite), actinolite and chlorite. The identification was difficult, due to the strong alteration of the sample material as shown in Figure 1. Microscopic investigations of the samples B1-J/H showed that many of the ore minerals were highly altered. The results of the polarization microscopy and XRD revealed that the ore mineral content and especially the sphalerite concentration was higher in sample B1-J compared to B1-H.

The mineral phases of B1 were quartz, calcite, minerals of the epidote group, garnet (spessartine andradite), pyrite, pyrrhotite, sphalerite and chlorite. To get more detailed information about the represented mineral phases and their composition, scanning electron microscopy in combination with EDX was performed on some phases of the samples A1-F and B1-J. The results of these investigations are summarized below.

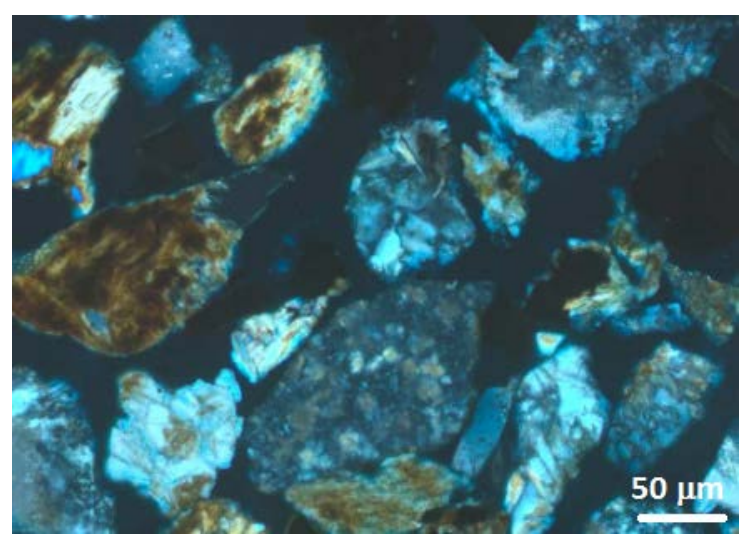

Figure 1. Polarization microscopy image of A1F-Bulk sample under crossed polarizers, showing heavily altered gangue grains.

\subsubsection{Detailed Study of Individual Sphalerites}

Microscopic examinations of the sphalerites in the samples (A1F-SM and B1-J) and their local analytic investigations revealed elevated iron content in the mineral phases. In addition to iron, admixtures of manganese and cadmium were detected. The sphalerite often contains inclusions of pyrrhotite or chalcopyrite; only in some cases structures of mineral intergrowth were also observed. The chemical compositions of a sphalerite and a pyrrhotite inclusion are shown in Table 5.

In addition to ore microscopy, further inclusions in sample A1F-SM were detected by electron beam microanalysis (EPMA-EDX) as galena, electrum, solid bismuth and various sulfosalts. Some of them are documented in the following section and shown in Figures 2 and 3. It should be noted that due to the size of the inclusions, surrounding phases were also excited, which may be reflected in the measurement results. Further investigations based on LA-ICPMS may help to minimize these inaccuracies. Significant is the presence of $\mathrm{Bi}, \mathrm{Ag}$ and $\mathrm{Au}$ because these elements might be of economic interest and justify further investigations. 
Table 5. Chemical composition of sphalerite with a pyrrothite inclusion in wt $\% /$ at $\%$ of sample B1-J (AN = atomic number, series = emitted X-ray series, unn. $\mathrm{C}=$ non corrected carbon, norm. $\mathrm{C}=$ normalized carbon, Atom. $\mathrm{C}=$ corrected atomic carbon).

\begin{tabular}{ccccccc}
\hline Element & AN & Series & unn. C (wt \%) & norm. C (wt \%) & Atom. C (at \%) & Error (wt \%) \\
\hline \multicolumn{6}{c}{ Sphalerite } \\
\hline $\mathrm{C}$ & 6 & $\mathrm{~K}$ & 13.3 & 13.02 & 37.21 & 2.6 \\
$\mathrm{~S}$ & 16 & $\mathrm{~K}$ & 29.9 & 29.27 & 31.34 & 1.1 \\
$\mathrm{Mn}$ & 25 & $\mathrm{~K}$ & 0.8 & 0.78 & 0.49 & 0.1 \\
$\mathrm{Fe}$ & 26 & $\mathrm{~K}$ & 12.33 & 12.07 & 7.42 & 0.4 \\
$\mathrm{Zn}$ & 30 & $\mathrm{~K}$ & 45.83 & 44.86 & 23.55 & 1.3 \\
\hline$\Sigma$ & & & 102.15 & 100 & 100 & \\
\hline & & & Pyrrhotite inclusion & \\
\hline $\mathrm{C}$ & 6 & $\mathrm{~K}$ & 15.17 & 14.4 & 37.99 & 2.9 \\
$\mathrm{~S}$ & 16 & $\mathrm{~K}$ & 33.68 & 31.97 & 31.58 & 1.2 \\
$\mathrm{Fe}$ & 26 & $\mathrm{~K}$ & 56.5 & 53.63 & 30.43 & 1.6 \\
\hline$\Sigma$ & & \multicolumn{7}{c}{105} & 100 & \\
\hline
\end{tabular}

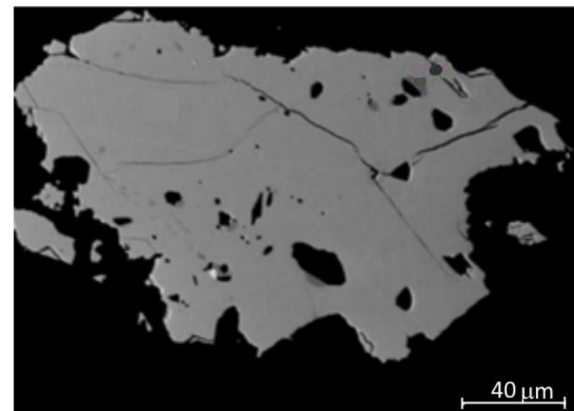

(a)

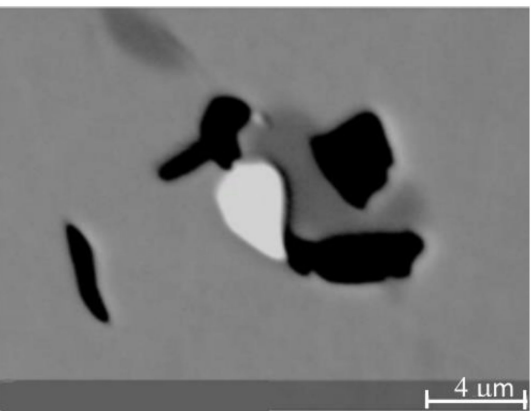

(b)

Figure 2. Sample A1F-SM: BSE image (EPMA) of sphalerite with inclusion of solid Bi (a) and BSE image (EPMA) of solid Bi inclusion surrounded by sphalerite and chalcopyrite (b).

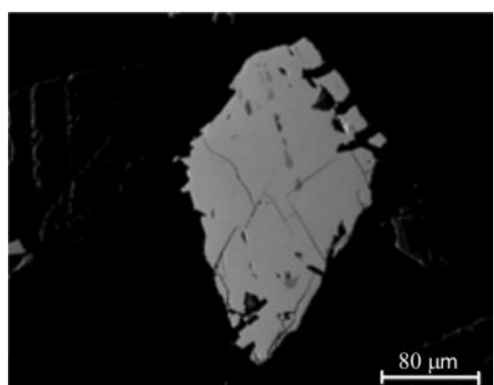

(a)

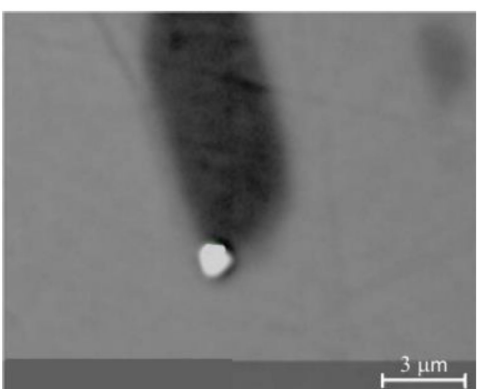

(b)

Figure 3. Sample A1F-SM: BSE image (EPMA). Sphalerite with inclusion of electrum and chalcopyrite (a) and BSE image (EPMA) of the magnification of the electrum inclusion (b).

From the representation of the chemical components of the Bi- and electrum inclusions of the sphalerite it becomes clear that these sphalerites can contain amounts of strategic elements like $\mathrm{Au}, \mathrm{Ag}$ and solid Bi (Tables 6 and 7). Especially the solid Bi concentration with over $80 \%$ is significant. Fe and $\mathrm{S}$ contents are as expected and typical for $\mathrm{Pb}$-Zn skarn deposits. High Fe contents in sphalerites are also an indicator of high formation temperatures [22]. 
Table 6. Chemical composition of Bi inclusion in wt \%/at \% (EPMA-EDX) (AN = atomic number, series $=$ emitted $\mathrm{X}$-ray series, unn. $\mathrm{C}=$ non corrected carbon, norm. $\mathrm{C}=$ normalized carbon, Atom. $\mathrm{C}=$ corrected atomic carbon).

\begin{tabular}{ccccccc}
\hline Element & AN & Series & unn. C (wt \%) & norm. C (wt \%) & Atom. C (at \%) & Error (wt \%) \\
\hline $\mathrm{S}$ & 16 & $\mathrm{~K}$ & 18.7 & 19.2 & 40.1 & 0.7 \\
$\mathrm{Fe}$ & 26 & $\mathrm{~K}$ & 6.8 & 6.9 & 8.3 & 0.3 \\
$\mathrm{Zn}$ & 30 & $\mathrm{~K}$ & 29.8 & 30.6 & 31.4 & 1.1 \\
$\mathrm{Ag}$ & 47 & $\mathrm{~K}$ & 18.7 & 19.2 & 12 & 0.8 \\
$\mathrm{Au}$ & 79 & $\mathrm{~K}$ & 23.4 & 24.1 & 8.2 & 0.9 \\
$\Sigma$ & & & 97.4 & 100 & 100 & \\
\hline
\end{tabular}

Table 7. Chemical composition of Au-Ag inclusion in wt \%/at \% (EPMA-EDX) (AN = atomic number, series $=$ emitted $\mathrm{X}$-ray series, unn. $\mathrm{C}=$ non corrected carbon, norm. $\mathrm{C}=$ normalized carbon, Atom. $\mathrm{C}=$ corrected atomic carbon).

\begin{tabular}{ccccccc}
\hline Element & AN & Series & unn. C (wt \%) & norm. C (wt \%) & Atom. C (at \%) & Error (wt \%) \\
\hline $\mathrm{S}$ & 16 & $\mathrm{~K}$ & 18.7 & 19.2 & 40.1 & 0.7 \\
$\mathrm{Fe}$ & 26 & $\mathrm{~K}$ & 6.8 & 6.9 & 8.3 & 0.3 \\
$\mathrm{Zn}$ & 30 & $\mathrm{~K}$ & 29.8 & 30.6 & 31.4 & 1.1 \\
$\mathrm{Ag}$ & 47 & $\mathrm{~K}$ & 18.7 & 19.2 & 12 & 0.8 \\
$\mathrm{Au}$ & 79 & $\mathrm{~K}$ & 23.4 & 24.1 & 8.2 & 0.9 \\
$\Sigma$ & & & 97.4 & 100 & 100 & \\
\hline
\end{tabular}

\subsubsection{MLA}

Mineral liberation analysis of the sphalerites of the heavy mineral sample indicated that the sphalerite occurs as an individual mineral aggregate. This could also be observed during the ore microscopy. The grains mostly occurred without direct intergrowth but inclusions of chalcopyrite and pyrrhotite were detected. Less than $5 \%$ of the sphalerites have a liberation degree below $90 \%$ and the intergrown minerals or inclusions detected are jarosite and amphibole, pyrite, chalcopyrite, pyrrhotite, quartz, Fe-oxides, anorthite, calcite and epidote. During the evaluation of the liberation degree by particle composition, the sphalerites are mostly fully liberated. Thus, $71.7 \%$ of all sphalerites detected in this sample were classified as 100\% liberated, another $21.1 \%$ were classified as 95 to $100 \%$ liberated and $3.8 \%$ should show 5 to $10 \%$ associations.

The sphalerite content detected by the mineral liberation analysis was at $2.9 \mathrm{wt} \%$ and for the X-ray powder diffractometry at $1.9 \mathrm{wt} \%$ and $0.9 \mathrm{wt} \%$ for the original sample, because of the different $\mathrm{wt} \%$ values, further analyses were of interest to get a clear impression. By use of the electron microprobe, average contents of the $\mathrm{Zn}(54.27 \mathrm{wt} \%)$ and S (33.72 wt \%) were obtained. Also, high Fe contents between 8 and $12.63 \mathrm{wt} \%$ were detected. Cadmium $(0.23 \mathrm{wt} \%)$ and manganese $(0.53 \mathrm{wt} \%)$ were measured as secondary elements.

Table 8 shows that the sphalerites of the heavy mineral fraction have not been lost to the tailings due to a lack of surface liberation. Possible reasons why they were rejected to the tailing stream could be the large grain size or a low $\mathrm{Zn}$ content. The calculated particle size distribution of sphalerite implies that approximately $35 \%$ of the grains are larger than $100 \mu \mathrm{m}$ and approximately $15 \%$ are between 150 and $200 \mu \mathrm{m}$. It has to be considered that the material of the analyzed thin sections was ground down to the $63-200 \mu \mathrm{m}$ fraction and differs from the grain size of the original sample, so it is not distinct if coarse sphalerites are left in the tailing material. 
Table 8. Mineral liberation degree by particle composition based on MLA data for sphalerite of the sample A1-SM.

\begin{tabular}{cc}
\hline Grading (Sphalerite) in \% & Liberation Class/Degree in \% \\
\hline 71.7 & 100 \\
21.1 & $95-100$ \\
3.8 & $90-95$ \\
Rest of 3.4 & $<90$ \\
\hline
\end{tabular}

Summarizing, the aforementioned investigations revealed a certain amount of coarse liberated sphalerites with varying degrees of iron content contained in the samples originating from different horizons. The sphalerites displayed a variety of inclusions, some of which are potentially of economic interest and bulk alterations. To assess the potential reprocessing of the tailing material, preliminary flotation tests were performed, which are discussed in the following section.

\subsection{Flotation Test Work}

The purpose of this flotation study was to determine a suitable reagent regime, allowing a reasonable recovery of sphalerite or zinc respectively and to provide data for a refinement of the LFC concept. The tests were performed with the B1 subsamples. Figure 4 shows the results of the flotation tests given as Fuerstenau plots with zinc recovery on the ordinate and the iron and sulfur recovery on the abscissa. The analysis was performed by $\mathrm{h}-\mathrm{XRF}$, and iron and sulfur are chosen to assess the selectivity against pyrite and pyrrhotite, while sphalerite, especially the high iron sphalerite, contains both elements.

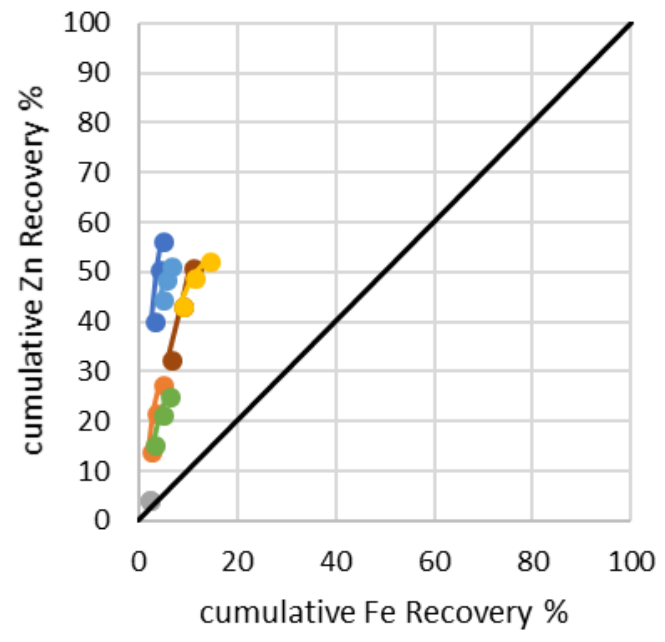

(a)

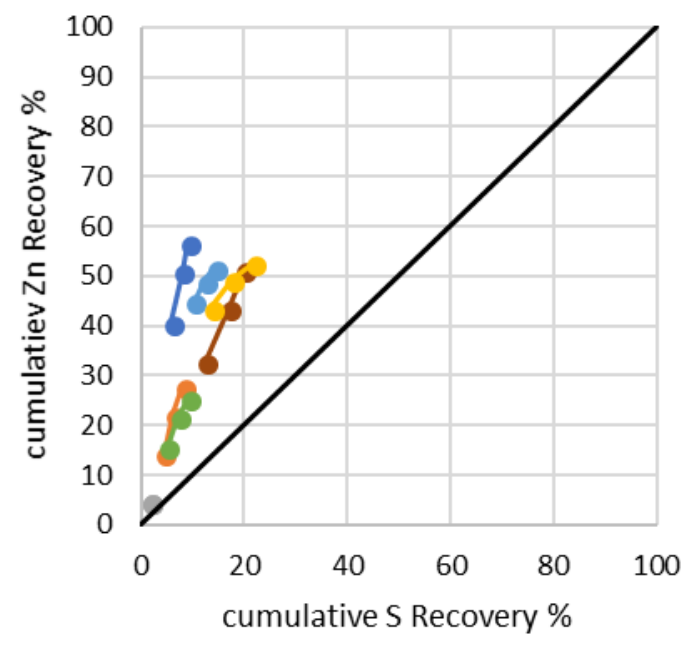

(b)

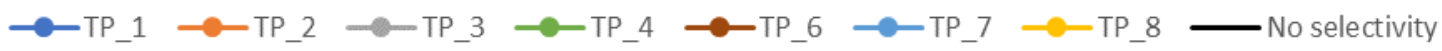

Figure 4. Fuerstenau plots of the flotation tests displaying cumulative $\mathrm{Zn}$ recovery to cumulative $\mathrm{Fe}$ recovery (a) and cumulative $\mathrm{Zn}$ recovery to cumulative $S$ recovery $(\mathbf{b})$.

The results of the flotation tests displayed in Figure 4 show a good selectivity against iron and sulphur for all tests. The highest selectivity and recovery was achieved with TP_1 resulting in a cumulative zinc recovery of $\sim 57 \%$. The utilization of KCN for TP_7 and TP_8 did not give an advantage in recovery or selectivity, possibly due to the high addition of $\mathrm{CuSO}_{4}$. The test TP_3 
indicates that close to no recovery is possible with no addition of an activator. Therefore, the sphalerite contained in the tailings has either not been activated in the initial process or was deactivated, while being contained in the dam. The experiment TP_5 was not considered, as an experimental error resulted in non-representative conditions.

Table 9 displays the cumulative zinc, iron and sulphur grades of the concentrates with the highest zinc grade achieved in sample TP_1 with iron and sulphur grades within the bandwidth of the other experiments.

Table 9. Cumulative zinc, iron and sulphur grades of the three concentrates per experiment.

\begin{tabular}{cccc}
\hline Sample & Zn Grade in \% & Fe Grade in \% & S Grade in \% \\
\hline TP_1 & 13 & 28 & 32 \\
TP_2 & 8 & 32 & 30 \\
TP_3 & 2 & 19 & 18 \\
TP_4 & 6 & 34 & 29 \\
TP_6 & 6 & 32 & 32 \\
TP_7 & 10 & 28 & 34 \\
TP_8 & 6 & 35 & 28 \\
\hline
\end{tabular}

\section{MLA Based Performance Assessment}

Based on the results of the flotation tests reported in the previous section, the sample TP_1 was chosen for detailed analysis by MLA, as it resulted in the highest zinc recovery and the highest selectivity with moderate addition of activator and collector.

The process result of the TP_1 sample is summarized in Table 10 based on the modal mineralogy of the calculated feed. The cumulative mineral grades in the concentrates are $29.5 \%$ for the sphalerite varieties, $39.5 \%$ sulfidic gangue and $31 \%$ other gangue minerals. The recoveries achieved are $58.8 \%$ for low iron sphalerite and $40.1 \%$ for the high iron variety with enrichment factors of 20.1 and 13.7 , respectively. The sulfidic gangue was also slightly enriched, while the non-sulfidic gangue minerals were depleted in the concentrates. The relatively low recoveries of the sphalerites will be analyzed in detail in the following by means of MLA-based data.

Table 10. Grade, recoveries and enrichment factor for TP_1.

\begin{tabular}{cccc}
\hline Minerals/Grouping & Concentrate Grade in wt \% & Recoveries in $\%$ & Enrichment Factor \\
\hline low iron sphalerite & 28.0 & 58.8 & 20.1 \\
high iron sphalerite & 1.5 & 40 & 13.7 \\
sulfidic gangue & 39.5 & 7.7 & 2.7 \\
gangue & 31.0 & 1.1 & 0.4 \\
\hline
\end{tabular}

Figure 5 shows the liberation and grade-recovery curves of the B1_TP_1 sample. Both curves are based on an ideal separation, where only sphalerite-containing particles are considered to be recovered to the concentrates and their associated minerals are responsible for gangue recovery and concentrate dilution. This simplification does not hold true for flotation due to entrainment in the froth and minerals, which are similarly reacting to the reagent regime, like other sulfidic gangue minerals. As the liberation and grade recovery curves display a good liberation, the low recovery has to be related to other material properties. Nevertheless, the selectivity of the chosen reagent regime is high, as displayed in the left graph indicated by the location of the three concentrates of the B1_TP_1 sample. 


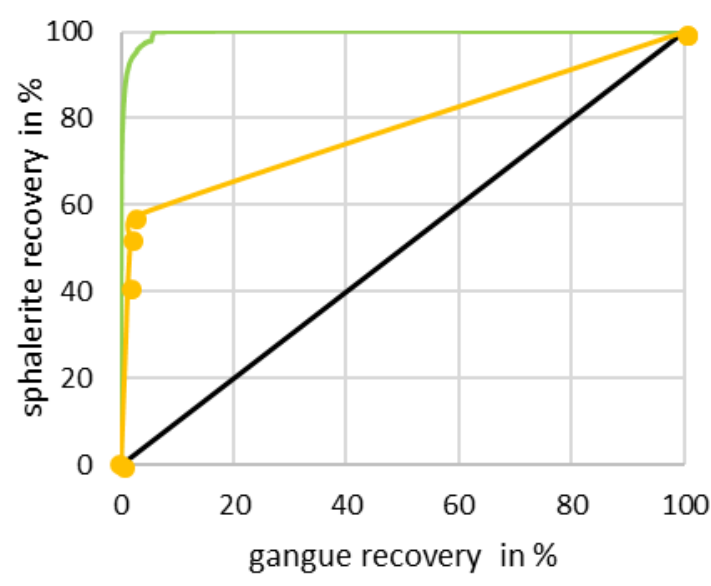

(a)

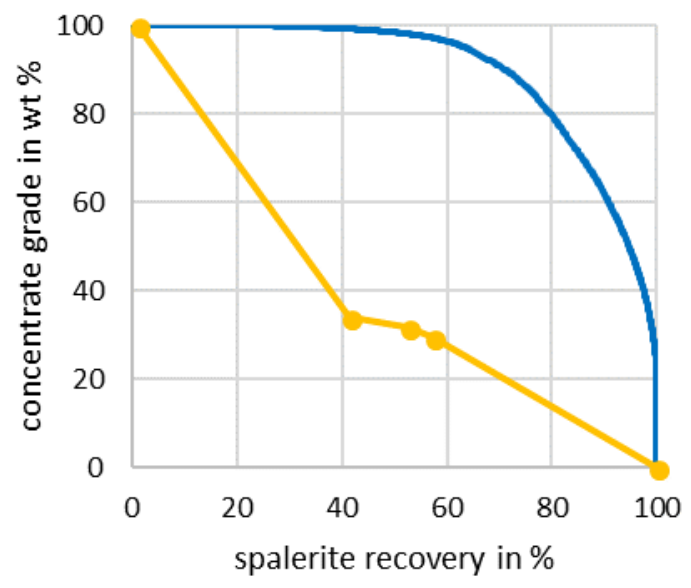

(b)

Sphalerite liberation curve $\longrightarrow$ Sphalerite grade-recovery curve - B1_TP_1 $\longrightarrow$ No separation

Figure 5. MLA-based Liberation curve (a) and grade-recovery curve (b) for B1_TP_1.

Figure 6 displays the sphalerite recovery by size and liberation classes (a) and the sphalerite abundance in the respective classes with the particle count per class (b). The highest recovery is achieved in the $60 \%$ to $80 \%$ surface liberation class in the size fraction $70 \mu \mathrm{m}$ to $150 \mu \mathrm{m}$. These classes comprise of 385 and 376 particles, but only represent $<5 \%$ of the total sphalerite content of the feed. Summarizing, a reasonable recovery can be achieved in the size classes above $20 \mu \mathrm{m}$ and surface liberation above $40 \%$. The sphalerite abundance plot indicates that the main share of the sphalerite is either in the $>150 \mu \mathrm{m}$ particle size fraction $(48 \%)$ and or in the $80-100 \%$ surface liberation classes (56\%) with the maximum of $\sim 20 \%$ at $80-100 \%$ surface liberation $>150 \mu \mathrm{m}$. This distribution is a result of the initial flotation performance of the material and therefore implicates an optimization of the initial flowsheet of the plant for the $>150 \mu \mathrm{m}$ fraction in terms of recovery of already liberated coarse particles and an optimized grind to increase the liberation, if the B1_TP_1 sample is considered to be representative of the currently processed material and no further refinements of the flowsheet were implemented earlier.

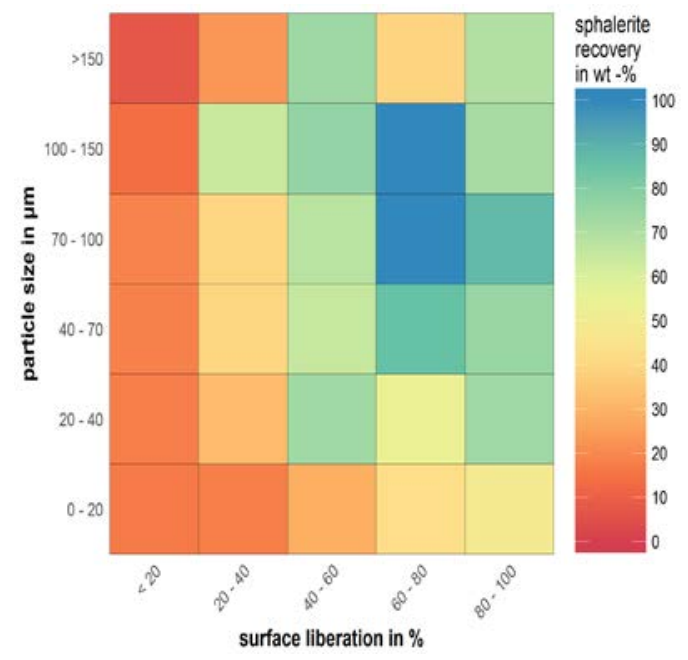

(a)

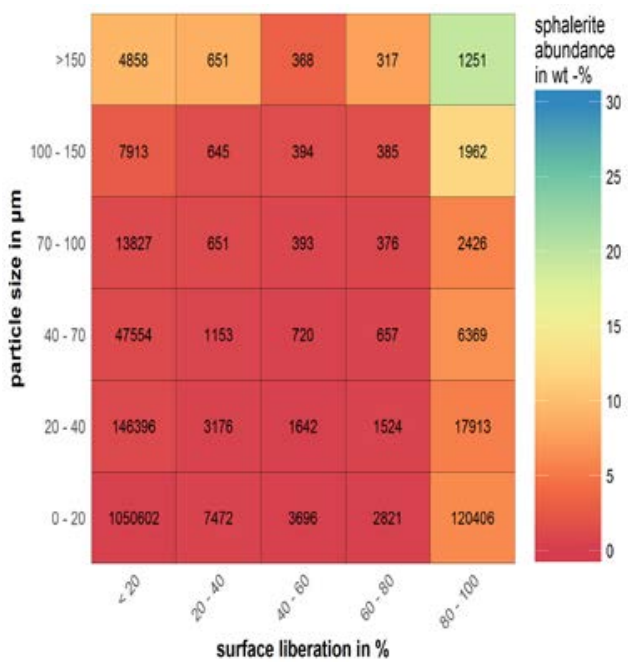

(b)

Figure 6. Sphalerite recovery by size and liberation (a), sphalerite abundance and particle count (b) for both varieties combined. 
Figure 7 shows the recovery by size for the TP_1 sample for the sulfidic gangue, low iron sphalerite, high iron sphalerite and other gangue minerals. Not considering different degrees of liberation, recoveries up to $79 \%$ can be achieved for the low iron sphalerite particles between 70 and $100 \mu \mathrm{m}$. Except for the dent at the 40-70 $\mu \mathrm{m}$ interval, the resulting curve comes close to the often reported bell shaped, or "Elephant" curve for flotation recoveries [36]. As reported in Figure 6, about $48 \%$ of the mass of particles containing sphalerite are found in the $>150 \mu \mathrm{m}$ fraction where the recovery drops more than $30 \%$ compared to the $70-100 \mu \mathrm{m}$ fraction probably caused by the broader distribution in the liberation classes. The reduced recovery in the $-20 \mu \mathrm{m}$ fraction is associated with the small particle size lowering the probability for bubble-particle attachment. This shortcoming might be overcome by adapted hydrodynamic conditions for fine particle flotation [8]. Figure 7 also illustrates the good selectivity of the chosen reagent regime resulting in relatively low recoveries of sulfidic and non-sulfidic gangue minerals for all size classes. This is also the case for the $-20 \mu \mathrm{m}$ size fraction where entrainment in the froth zone becomes problematic. The recovery shown for the high iron sphalerite is lower than for the low iron sphalerite, but it still can be enriched to a certain extend. In the coarser fractions, the flotation behavior might be explained by the mineral association as shown in Figure 8.

In Figure 8 the mineral associations of the high and low iron sphalerite in concentrate and tailings are depicted. As shown in graph (a), the high iron sphalerite in the size classes above $70 \mu \mathrm{m}$, where most of it was recovered, is mostly associated to low iron sphalerite. In comparison to graph (b), with a similar percentage of free surface but a lower association to low iron sphalerite, it seems that the recovery of high iron sphalerite shown in Figure 7 is mostly driven by the mineral association of high to low iron sphalerite. The $<20 \mu \mathrm{m}$ size fraction of the high iron sphalerite has about $70 \%$ free surfaces but only $25 \%$ percent was recovered. Therefore, the chosen reagent regime seems to result in an intermediate hydrophobicity for the high iron sphalerites. Graph (c) and (d) indicate a good liberation for low iron sphalerite in the lower size classes and that a regrind for the coarser size classes or tailings regrind are options to improve the overall recovery. As shown above, the recovery of the high iron sphalerite is most likely caused by the association to the low iron sphalerite and a regrind of the intermediate size classes might result in a drop in high iron sphalerite recovery. For further test work, two options seem feasible. The first option is a regrind of the $>150 \mu \mathrm{m}$ size fraction, which could result in an overgrind and an increase in fine gangue particles.

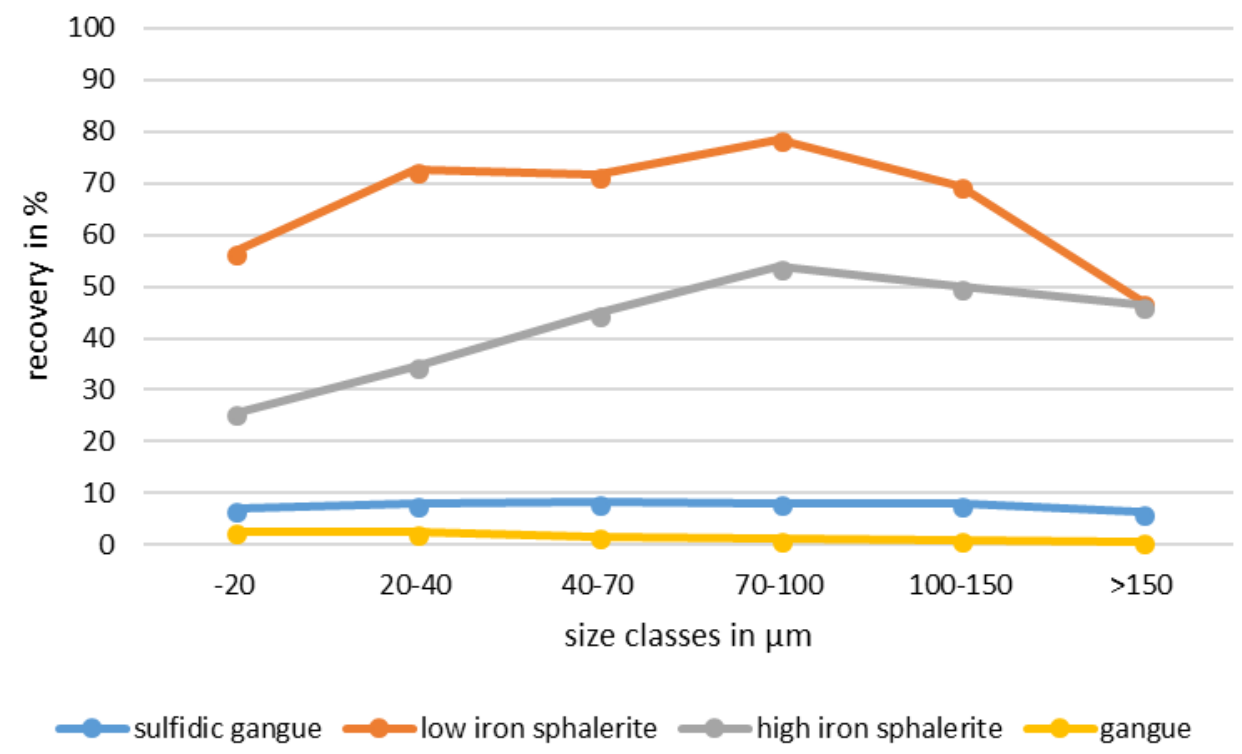

Figure 7. Recovery by size classes for grouped minerals of B1_TP_1. 


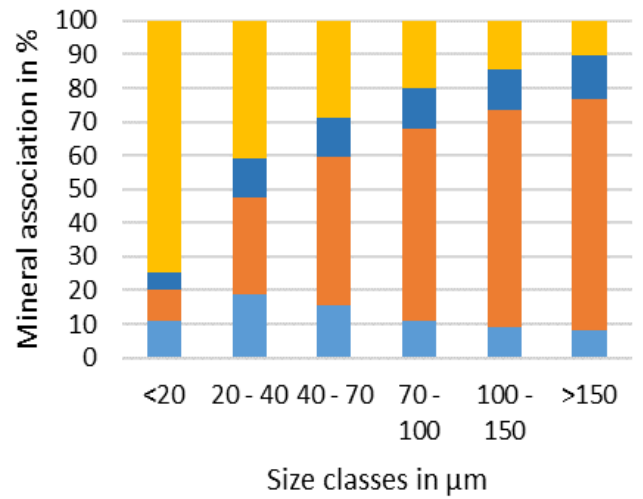

(a)

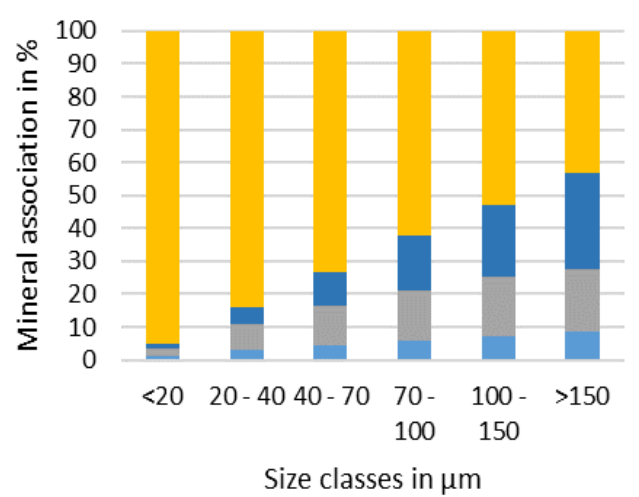

(c)

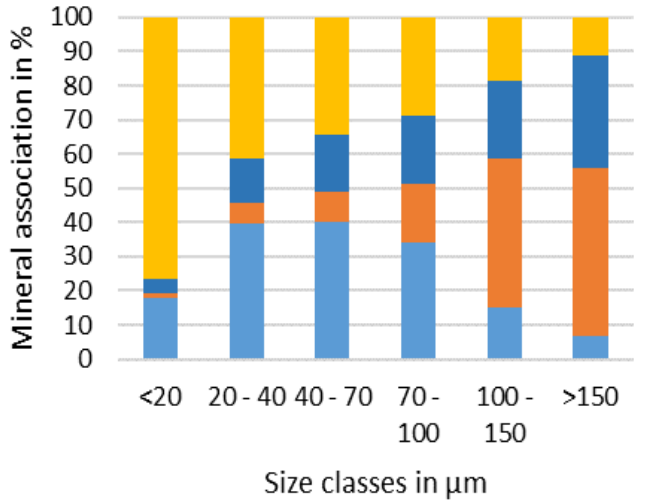

(b)

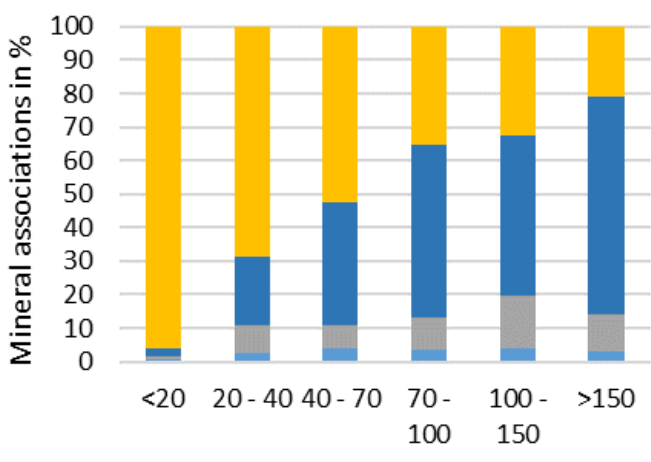

Size classes in $\mu \mathrm{m}$

(d)

$$
\text { wigh iron sphalerite } \quad \text { sulfidic gangue } \quad \text { free surface } \quad \text { low iron sphalerite gangue }
$$

Figure 8. Mineral associations in concentrates $(\mathbf{a}, \mathbf{c})$ and tailings $(\mathbf{b}, \mathbf{d})$ for high $(\mathbf{a}, \mathbf{b})$ and low iron sphalerite $(\mathbf{c}, \mathbf{d})$.

This could be detrimental to flotation performance in a mechanical lab scale cell as reported by Reference [10]. Another aspect to consider is the effect of superficial gas velocity and particle size on dynamic froth stability. Mackay et al. reported two regimes of the relationship of froth stability and particle size distribution in a laboratory scale flotation column. At a set superficial gas velocity the highest copper recovery was achieved by a local maximum of dynamic froth stability, with an overall decreasing froth stability with increasing $\mathrm{d} 90$ values. The authors suggested when operating at higher particle size distributions a certain amount of fine particles in the system can be beneficial to dynamic froth stability and flotation performance [17]. The second option is a focus on coarse particle recovery, for example with a Jameson cell and a reported maximum floating particle size of $200 \mu \mathrm{m}$ to $320 \mu \mathrm{m}$ depending on the contact angle as reported by Reference [37] or other concepts focusing on coarse particle recovery [7]. Additionally, a regrind of the coarse particle flotation tailing stream could be reasonable to improve the liberation for standard flotation test work.

\section{Discussion}

The results of the mineralogical investigations showed a reasonable amount of liberated coarse sphalerite contained in the samples A1 and B1. While being heavily altered, certain inclusions contained in the sphalerite could be of economic interest. A certain amount of sphalerite can be selectively recovered by means of flotation reaching a recovery of $59 \%$ and $40 \%$ for both sphalerite varieties contained in the tailings. The detailed analysis by SEM-based image data revealed recoveries 
up to $100 \%$ for certain size and liberation classes and an inhomogeneous distribution of valuables in the flotation feed. The shortcomings in recovery are based on the increased abundance of sphalerite in a particle size class $>150 \mu \mathrm{m}$ over the whole range of liberation classes. The main driver for the recovery of the high iron variant seems to be association to the low iron sphalerite. A possible regrind option could potentially lead to a decline in high iron sphalerite recovery.

The results of the flotation test work can in the future be utilized to calculate a weighting function named " $\mathrm{LCF}$ " as reported by Buettner et al. The "LCF" was used to highlight regions in a cassiterite tailings dam, which were considered most suitable for the recovery of cassiterite in a geometallurgical 3D-model [16]. The acronym "LCF" reflects a product calculated from three indices named IC (0-100), IL (0-1) and IP (0-1), where IC is an index for valuable concentration, IL reflects an index of liberation and IP as an index of particle size. The author proposed IC as a linear function increasing with the valuable concentration and a nonlinear function for IL scaling with the surface liberation [16]. The index IP is based on a favorable size range for flotation between $10 \mu \mathrm{m}$ to $45 \mu \mathrm{m}$, which can be considered an unrealistic choice in a general consideration of flotation processes. In the case of experimental data for flotation recovery, IL and IP could be replaced by the normalized recovery of the experimental size and liberation classes. An alternative to direct application of this is the extraction of a characteristic line for sphalerite particle recovery as depicted in Figure 9. The line was derived from an equation fitted to the experimental data for the 60-100\% surface liberation classes, as displayed in Figure 6. An alternative option not relying on own experimental data could be derived from the recovery by size curves in base metal production as reported in Reference [36] and implemented into the concept reported by Reference [16].

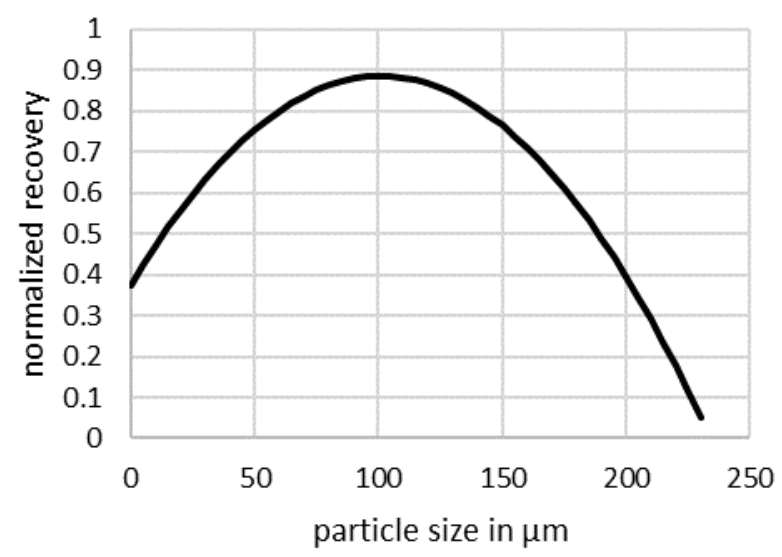

Figure 9. Characteristic line for sphalerite particle recovery derived from experimental results.

Considering technological developments in flotation with a focus on fine [8] and coarse particle recovery [7,37], the application of the aforementioned options within the LCF and 3D modelling concept might not reflect the optimum conditions for valuable recovery, but result in a good indicator for reprocessing potentials and their distribution within tailing dams. In this case, the LFC approach can be beneficial as the valuables and possibly problematic minerals are distributed heterogeneously within the sampled horizons as depicted in Table 3. Further refinements of the LFC weighing function should be a selectivity factor SI for potentially problematic gangue minerals, in this case other sulfides.

\section{Conclusions}

In this paper, detailed analysis of a tailings dam in southern Chile was performed with the objective to assess the possible reprocessing of the contained sphalerite. Based on initial investigations, which revealed a high amount of coarse and liberated sphalerite particles, flotation was chosen as a possible process for sphalerite recovery. The process parameters were based on data reported in literature. The most promising test was analyzed in detail, based on MLA with emphasis on liberation, 
size classes and sphalerite abundance in the regarding size and liberation classes. The utilized reagent regime achieved a high selectivity against sulfidic and non-sulfidic gangue in single batch flotation tests, with low recovery despite having a good overall liberation. This shortcoming can be explained by the distribution of sphalerite in the feed material and is used to propose an optimized test work procedure. Based on these findings we additionally propose changes in the already existing flowsheet for the plant to optimize the recovery of coarse-liberated sphalerite either by further comminution or the utilization of devices optimized for coarse particle recovery and an optimization of the grinding circuit to achieve a higher surface liberation of coarse-locked sphalerite.

Author Contributions: Conceptualization, B.B. and M.P.; Investigation, S.B.; Visualization, E.S.; Writing-original draft, B.B. and M.P.; Writing-review \& editing, B.B., M.P., S.B., E.S. and M.R.

Funding: This research was funded by the POF III (project oriented funding) of the Helmholtz Foundation designated for Flotation Research in the EMR program under subtopic 5 (resource technologies) and by the Germany Federal Ministry of Education and Research (BMBF) project Secondary Mining (SecMinStratEl) (Grant No. (FKZ) 033R118A) as a port of the CLIENT-program.

Acknowledgments: The authors thank Silke Thümmler of the MVTAT, TU Bergakademie Freiberg for the helium pycnometer measurement, Maria Ussath of the Institute of Mining at the TU Bergakademie Freiberg for the XRF measurement and Thomas Heinig of the Helmholtz Institute Freiberg for the MLA measurements as well as Frank Haubrich (Erz und Stein/GEOS) and Wilhelm Nikonow (BGR, Hanover, Germany).

Conflicts of Interest: The authors declare no conflict of interest

\section{References}

1. Falagán, C.; Grail, B.M.; Johnson, D.B. New approaches for extracting and recovering metals from mine tailings. Miner. Eng. 2017, 106, 71-78. [CrossRef]

2. Lottermoser, B. Mine Wastes: Characterization, Treatment and Environmental Impacts; Springer: Berlin/Heidelberg, Germany, 2010.

3. Wang, C.; Harbottle, D.; Liu, Q.; Xu, Z. Current state of fine mineral tailings treatment: A critical review on theory and practice. Miner. Eng. 2014, 58, 113-131. [CrossRef]

4. Kausch, P.; Bertau, M.; Gutzmer, J.; Matschullat, J. Strategische Rohstoffe-Risikovorsorge; Springer: Berlin/Heidelberg, Germany, 2013.

5. Fandrich, R.; Gu, Y.; Burrows, D.; Moeller, K. Modern SEM-based mineral liberation analysis. Int. J. Miner. Process. 2007, 84, 310-320. [CrossRef]

6. $\mathrm{Gu}, \mathrm{Y}$. Automated scanning electron microscope based mineral liberation analysis an introduction to JKMRC/FEI mineral liberation analyser. J. Miner. Mater. Charact. Eng. 2003, 2, 33-41. [CrossRef]

7. Kohmuench, J.N.; Mankosa, M.J.; Thanasekaran, H.; Hobert, A. Improving coarse particle flotation using the HydroFloat $^{\mathrm{TM}}$ (raising the trunk of the elephant curve). Miner. Eng. 2018, 121, 137-145. [CrossRef]

8. Mankosa, M.J.; Kohmuench, J.N.; Christodoulou, L.; Yan, E.S. Improving fine particle flotation using the StackCell ${ }^{\mathrm{TM}}$ (raising the tail of the elephant curve). Miner. Eng. 2018, 121, 83-89. [CrossRef]

9. Leistner, T.; Embrechts, M.; Leißner, T.; Chehreh Chelgani, S.; Osbahr, I.; Möckel, R.; Peuker, U.A.; Rudolph, M. A study of the reprocessing of fine and ultrafine cassiterite from gravity tailing residues by using various flotation techniques. Miner. Eng. 2016, 96, 94-98. [CrossRef]

10. Leistner, T.; Peuker, U.A.; Rudolph, M. How gangue particle size can affect the recovery of ultrafine and fine particles during froth flotation. Miner. Eng. 2017, 109, 1-9. [CrossRef]

11. Videla, A.R.; Morales, R.; Saint-Jean, T.; Gaete, L.; Vargas, Y.; Miller, J.D. Ultrasound treatment on tailings to enhance copper flotation recovery. Miner. Eng. 2016, 99, 89-95. [CrossRef]

12. Bryan, C.G.; Hallberg, K.B.; Johnson, D.B. Mobilisation of metals in mineral tailings at the abandoned São Domingos copper mine (Portugal) by indigenous acidophilic bacteria. Hydrometallurgy 2006, 83, 184-194. [CrossRef]

13. Ahmadi, A.; Khezri, M.; Akbar Abdollahzadeh, A.; Askari, M. Bioleaching of copper, nickel and cobalt from the low grade Sulfidic tailing of Golgohar iron mine, Iran. Hydrometallurgy 2015, 154, 1-8. [CrossRef]

14. Okrusch, M.; Matthes, S. Mineralogie: Eine Einführung in die spezielle Mineralogie, Petrologie und Lagerstättenkunde; Springer: Berlin/Heidelberg, Germany, 2013.

15. Lottermoser, B.G. Recycling, reuse and rehabilitation of mine wastes. Elements 2011, 7, 405-410. [CrossRef] 
16. Büttner, P.; Osbahr, I.; Zimmermann, R.; Leißner, T.; Satge, L.; Gutzmer, J. Recovery potential of flotation tailings assessed by spatial modelling of automated mineralogy data. Miner. Eng. 2018, 116, 143-151. [CrossRef]

17. Mackay, I.; Mendez, E.; Molina, I.; Videla, A.R.; Cilliers, J.J.; Brito-Parada, P.R. Dynamic froth stability of copper flotation tailings. Miner. Eng. 2018, 124, 103-107. [CrossRef]

18. Clemente, D.; Newling, P.; Botelho de Sousa, A.; LeJeune, G.; Barber, S.P.; Tucker, P. Reprocessing slimes tailings from a tungsten mine. Miner. Eng. 1993, 6, 831-839. [CrossRef]

19. Lutandula, M.S.; Maloba, B. Recovery of cobalt and copper through reprocessing of tailings from flotation of oxidised ores. J. Environ. Chem. Eng. 2013, 1, 1085-1090. [CrossRef]

20. Alcalde, J.; Kelm, U.; Vergara, D. Historical assessment of metal recovery potential from old mine tailings: A study case for porphyry copper tailings, Chile. Miner. Eng. 2018. [CrossRef]

21. Yang, X.; Huang, X.; Qiu, T. Recovery of zinc from cyanide tailings by flotation. Miner. Eng. 2015, 84, $100-105$. [CrossRef]

22. Bussey, S.D.; Kakarieka, A.; Meinert, L.D. Skarn, Porphyry, Vein, and Replacement Mineralization in the Toqui District, Southern Chile. In The Challenge of Finding New Mineral Resources: Global Metallogeny, Innovative Exploration, and New Discoveries; Goldfarb, R.J., Marsh, E.E., Monecke, T., Eds.; Society of Economic Geologists: Littleton, CO, USA, 2010.

23. Bulatovic, S.M. 14-Flotation of Lead-Zinc Ores. In Handbook of Flotation Reagents; Elsevier: Amsterdam, The Netherlands, 2007; pp. 323-366.

24. Chandra, A.P.; Gerson, A.R. A review of the fundamental studies of the copper activation mechanisms for selective flotation of the sulfide minerals, sphalerite and pyrite. Adv. Colloid Interface Sci. 2009, 145, 97-110. [CrossRef] [PubMed]

25. Finkelstein, N.P. The activation of sulphide minerals for flotation: A review. Int. J. Miner. Process. 1997, 52, 81-120. [CrossRef]

26. Boulton, A.; Fornasiero, D.; Ralston, J. Effect of iron content in sphalerite on flotation. Miner. Eng. 2005, 18, 1120-1122. [CrossRef]

27. Albrecht, T.W.J.; Addai-Mensah, J.; Fornasiero, D. Critical copper concentration in sphalerite flotation: Effect of temperature and collector. Int. J. Miner. Process. 2016, 146, 15-22. [CrossRef]

28. Tong, X.; Song, S.; He, J.; Rao, F.; Lopez-Valdivieso, A. Activation of high-iron marmatite in froth flotation by ammoniacal copper(II) solution. Miner. Eng. 2007, 20, 259-263. [CrossRef]

29. Clarke, P.; Fornasiero, D.; Ralston, J.; Smart, R.S.C. A study of the removal of oxidation products from sulfide mineral surfaces. Miner. Eng. 1995, 8, 1347-1357. [CrossRef]

30. Boulton, A.; Fornasiero, D.; Ralston, J. Depression of iron sulphide flotation in zinc roughers. Miner. Eng. 2001, 14, 1067-1079. [CrossRef]

31. Sun, W.; Liu, R.-Q.; Cao, X.-F.; Hu, Y.-H. Flotation separation of marmatite from pyrrhotite using DMPS as depressant. Trans. Nonferr. Met. Soc. China 2006, 16, 671-675. [CrossRef]

32. He, M.-F.; Qin, W.-Q.; Li, W.-Z.; Zeng, K. Pyrite depression in marmatite flotation by sodium glycerine-xanthate. Trans. Nonferr. Met. Soc. China 2011, 21, 1161-1165. [CrossRef]

33. Sinclair, R.J. The Extractive Metallurgy of Zinc; AusIMM: Carlton, Australia, 2005.

34. Zhang, G.; Germaine, J.T.; Martin, R.T.; Whittle, A.J. A simple sample-mounting method for random powder X-ray diffraction. Clays Clay Miner. 2003, 51, 218-225. [CrossRef]

35. Doebelin, N.; Kleeberg, R. Profex: A graphical user interface for the Rietveld refinement program BGMN. J. Appl. Crystallogr. 2015, 48, 1573-1580. [CrossRef] [PubMed]

36. Lynch, A.J.; Johnson, N.W.; Manlapig, E.V.; Thorne, C.G. Mineral and Coal Flotation Circuits-Their Simulation and Control, Developments in Mineral Processing Series; Elsevier Scientific Publishing Company: New York, NY, USA, 1981.

37. Şahbaz, O.; Uçar, A.; Öteyaka, B. Velocity gradient and maximum floatable particle size in the Jameson cell. Miner. Eng. 2013, 41, 79-85. [CrossRef]

(C) 2018 by the authors. Licensee MDPI, Basel, Switzerland. This article is an open access article distributed under the terms and conditions of the Creative Commons Attribution (CC BY) license (http:// creativecommons.org/licenses/by/4.0/). 